\title{
Representasi Matematis Siswa Tuna Rungu dalam Menyelesaikan Soal Cerita Matematika
}

\author{
Elis Dwi Wulandari ${ }^{1}$, Erry Hidayanto ${ }^{1}$, Rustanto Rahardi ${ }^{1}$ \\ ${ }^{1}$ Pendidikan Matematika-Universitas Negeri Malang
}

\begin{tabular}{l}
\hline \hline INFO ARTIKEL \\
\hline Riwayat Artikel: \\
Diterima: 07-05-2019 \\
Disetujui: 26-07-2019 \\
\hline
\end{tabular}

\section{Kata kunci:}

mathematical representation; mathematical expression; deaf students;

representasi matematis; ekspresi matematis; siswa tuna rungu

\author{
Alamat Korespondensi: \\ Elis Dwi Wulandari \\ Pendidikan Matematika \\ Universitas Negeri Malang \\ Jalan Semarang 5 Malang \\ E-mail: elis.dwi.1703118@ students.um.ac.id
}

\begin{abstract}
Mathematical representation is the way of communicating mathematical ideas and problems solutions. Communicating mathematical ideas requires external representation in the form of actions, verbal, symbolic, visual and real objects. This study aims to describe the form of representation of Deaf Students in solving mathematical story problems. The research was conducted by giving types of text questions as well as text and image questions to three DS at Banyuwangi State of Special Need High School. The results of student work analysis found that there are two types of mathematical representations that appear in solving story problems, namely verbal representation indicated by writing words, numbers, letters, sentences and oral and representation of mathematical expressions in the form of symbols and numbers. DS are able to representing, make mathematical symbols, explain in writing or sign language what they think are.
\end{abstract}

ABSTRAK

\begin{abstract}
Abstrak: Representasi matematis adalah cara mengomunikasikan ide-ide matematis maupun solusi permasalahan. Mengomunikasikan ide-ide matematis diperlukan representasi eksternal berbentuk tindakan, verbal, simbolik, visual dan objek nyata. Studi ini bertujuan untuk mendeskripsikan bentuk representasi siswa Tuna Rungu dalam menyelesaikan soal cerita matematika. Penelitian dilakukan dengan memberikan jenis soal teks serta soal teks dan gambar kepada tiga siswa TR di SMALBN Banyuwangi. Hasil analisis pekerjaan siswa ditemukan terdapat dua tipe bentuk representasi matematis yang muncul dalam menyelesaikan soal cerita, yaitu representasi verbal yang ditunjukkan dengan tulisan kata, angka, huruf, kalimat serta lisan dan representasi ekspresi matematis berupa simbol dan angka. Siswa TR mampu merepresentasikan, membuat simbol matematis, menjelaskan dengan tulisan maupun bahasa isyarat apa yang mereka pikirkan.
\end{abstract}

Cara yang digunakan untuk mengomunikasikan ide-ide matematis maupun solusi dari masalah yang sedang dihadapi merupakan pengertian dari representasi. Dalam NCTM (2000), istilah representasi mangacu pada memproses dan menghasilkan, untuk tindakan menangkap konsep matematika atau hubungan pada beberapa bentuk dan untuk bentuk itu sendiri. Representasi matematis sangat dibutuhkan dalam pemahaman konsep, penyelesaian maslaah matematis dan pengomunikasian ide-ide matematis oleh siswa. Dalam mengomunikasikan ide-ide matematis diperlukan representasi eksternal yang berbentuk tindakan (contextual), verbal, simbolik, visual, dan objek nyata (physical) (NCTM, 2000). Representasi eksternal berfungsi untuk: (1) memberikan informasi kepada guru mengenai bagaimana siswa berpikir tentang konten atau ide matematis, (2) memberikan informasi tentang pola dan kecenderungan siswa, dan (3) alat bantu dalam proses pembelajaran.

Representasi siswa berguna untuk menggambarkan, mengomunikasikan objek matematika, menyelesaikan permasalahan dalam matematika dan dengan matematika. Dalam mengonstruksikan pengetahuan, penting jika siswa dapat merepresentasikannya agar dapat diketahui sampai sejauh mana pengetahuan yang mereka miliki. Menurut Boonen (2014), berhasilnya masalah yang terpecahkan oleh siswa, tidak lepas dari peran representasi. Sesuai yang dikemukakan oleh Rahmad (2016) bahwa representasi matematis adalah kunci keberhasilan dalam memahami konsep matematika dan pemecahan masalah. Representasi matematis terdiri dari representasi simbolik dan representasi verbal (Anwar, 2017).

Simbol matematis dapat digunakan siswa untuk melakukan serangkaian perhitungan serta memfasilitasi siswa dalam memecahkan masalah, salah satunya memudahkan siswa sehingga dapat merepresentasikan apa yang mereka pikirkan. Bentuk representasi verbal digunakan sesuai dengan apa yang siswa pahami berdasarkan informasi yang diketahui. Representasi verbal dan tulis, dapat membantu para guru dalam memahami cara belajar siswa dan bagaimana menggunakan bahasa matematika (Sealey, 2014). Penelitian terkait pentingnya representasi dalam matematika, antara lain dilakukan oleh Sealey dkk. (2014), Boonen dkk. (2014), Anwar (2017), dan van Garderen (2018). Menurut van Garderen (2018), representasi visual dalam 
matematika adalah praktik yang sangat direkomendasikan di pendidikan. Boonen (2014) juga menjelaskan beberapa tipe representasi visual yang digunakan siswa dalam memecahkan permasalahan matematis. Representasi visual sering membantu dalam memahami masalah. Menggunakan representasi visual mengarah ke pemahaman yang lebih baik dan meningkatkan penalaran matematis khusus (Debrenti, 2015).

Representasi yang dimiliki oleh masing-masing siswa dalam menyelesaikan masalah matematis berbeda-beda. Karenanya, mengetahui hasil interpretasi pemikiran siswa ditinjau dari bagaimana siswa tersebut merepresentasikan dan menyelesaikan permasalahan matematis yang diberikan, dapat mendukung pemilihan strategi atau metode yang digunakan dalam pembelajaran. Pemilihan strategi ataupun metode yang tepat akan memperlancar proses pembelajaran serta menjadi efektif dan tujuan pembelajaran dapat tercapai. Hal tersebut menunjukkan bahwa perlu mengetahui bagaimana representasi matematis siswa dalam menyelesaikan permasalahan matematis. Pada dunia pendidikan, tidak banyak orang mengetahui hasil interpretasi siswa berkebutuhan khusus dalam menyelesaikan permasalahan matematis. Secara umum, yang diketahui adalah bagaimana cara siswa berkebutuhan khusus untuk berkomunikasi sehari-sehari. Mengetahui bagaimana representasi matematis siswa berkebutuhan khusus menjadi tantangan baru dalam pendidikan untuk dapat mencapai tujuan pembelajaran layaknya siswa pada sekolah umum lainnya.

Siswa berkebutuhan khusus salah satunya adalah siswa tuna rungu. Siswa tuna rungu adalah siswa dengan keterbatasan indera pendengaran. Dalam berkomunikasi, siswa tuna rungu menggunakan bahasa isyarat khusus. Selain memiliki keterbatasan pendengaran, juga memiliki keterbatasan dalam berucap. Karena tidak dapat mendengarkan, maka dia tidak dapat menirukan bagaimana suatu bunyi ditimbulkan. Siswa tuna rungu akan lebih banyak melihat, menulis dan bergerak daripada mendengarkan. Ingatan mereka terfokus pada gerakan dan kata-kata yang pernah mereka lihat. Menurut Marschark (2012), anak-anak tuna rungu tidak mendengar anak-anak yang tidak dapat mendengar. Anak tuna rungu dan yang dapat mendengar memiliki pengetahuan, latar belakang, pengalaman dan strategi belajar yang berbeda. Lalu, bagaimanakah siswa tuna rungu dalam pembelajaran? Berikut disajikan hasil observasi awal pada siswa tuna rungu di SMALBN Banyuwangi. Hasil observasi awal menunjukkan bagaimana siswa tuna rungu dalam mengolah kata-kata, seperti terlihat pada gambar 1.

\begin{tabular}{|c|c|}
\hline$\square$ & Buatlah kalimat dengan kata \\
\hline \multicolumn{2}{|r|}{ (2) } \\
\hline 0 & Kipas angin \\
\hline 2 & Buku \\
\hline 3 & Papan tulis \\
\hline 4. & Sapu \\
\hline 5. & Pengagaris \\
\hline \multicolumn{2}{|l|}{$\square$} \\
\hline \multicolumn{2}{|l|}{$\square$} \\
\hline 1 & Kqlas angin \\
\hline$\square$ & saya pergr ke toko untuk membeir kipas angin \\
\hline$\square$ & kalu saya bawa pulang dan kipasangin'sanat \\
\hline$\square$ & kencang \\
\hline \multicolumn{2}{|l|}{$\square$} \\
\hline 2 & 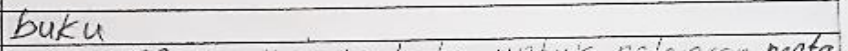 \\
\hline$\square$ & saya mempunya 10 buka untuk peigaran mata \\
\hline \multicolumn{2}{|r|}{ 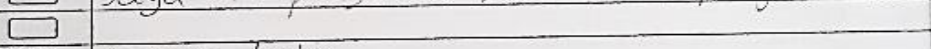 } \\
\hline 3 & papan tulis \\
\hline$\square$ & berwarna put is bentuk perseg panjang buat \\
\hline$\square$ & kayu dan papan di depan kelas \\
\hline \multicolumn{2}{|r|}{ Eaga ain $r$ i } \\
\hline स & 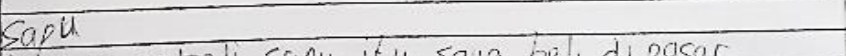 \\
\hline$\square$ & besar sekali sapu itu saya beli di pasar \\
\hline$\square$ & bersama anak-anak \\
\hline \multicolumn{2}{|r|}{ Dersama cua ure } \\
\hline 5 & Denggaris \\
\hline$\square$ & saya membell penggaris di toko alat iulis \\
\hline 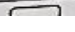 & \\
\hline
\end{tabular}

\section{Gambar 1. Hasil Pekerjaan S1 dalam Menyusun Kalimat}

Hasil pekerjaan siswa tuna rungu pertama (S1) dalam tugas membuat kalimat pada pelajaran bahasa Indonesia ditunjukkan pada gambar 1. Pada Gambar 1, kalimat nomor 2 menunjukkan bahwa siswa memiliki permasalahan dalam penyusunan kalimat. "Saya mempunyai 10 buku untuk pelajaran mata" yang berarti "Saya mempunyai 10 buku untuk mata pelajaran", sehingga yang dimaksud bukan "pelajaran mata", tetapi "mata pelajaran", misal matematika, kimia, biologi, dan lain lain. Selain siswa S1, gambar 2 menunjukkan pekerjaan siswa tuna rungu kedua (S2) dalam membuat kalimat bahasa Indonesia. 


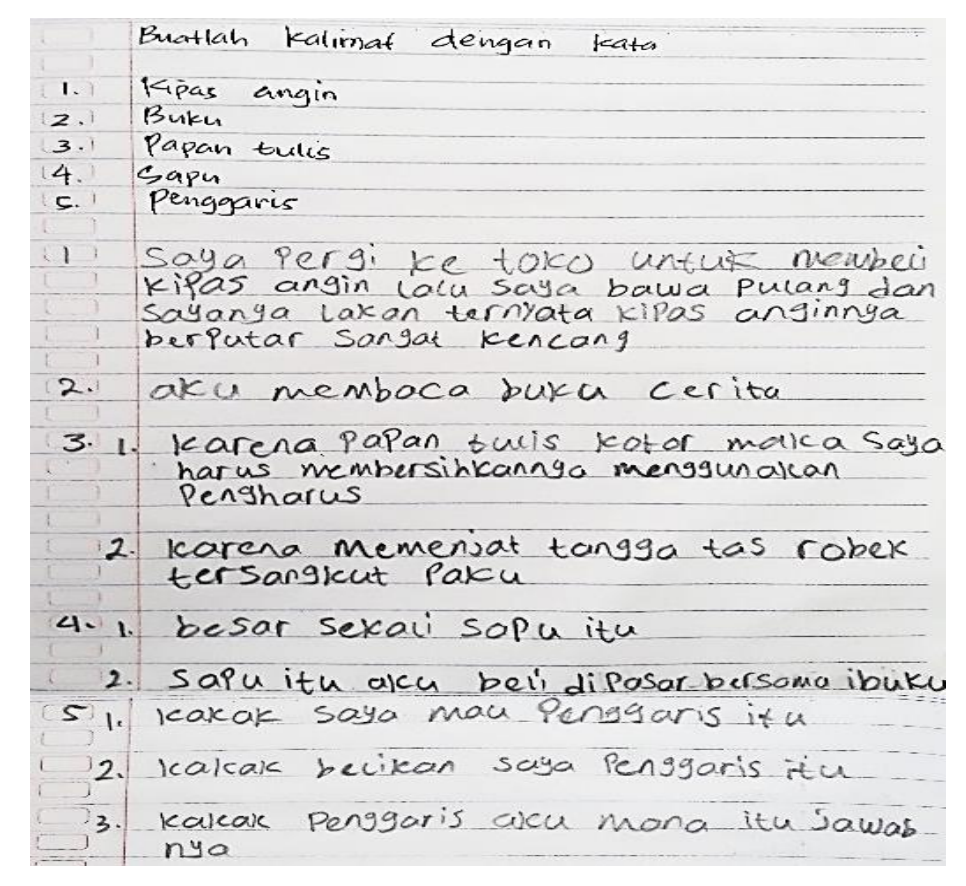

\section{Gambar 2. Hasil Pekerjaan S2 dalam Menyusun Kalimat}

Gambar 2 menunjukkan hasil pekerjaan siswa tuna rungu kedua (S2) dalam menyusun kalimat bahasa Indonesia. Pada pekerjaan nomor 5 poin ke 3, terlihat bahwa terdapat permasalahan yang dilakukan S2 dalam menyusun kata-kata menjadi kalimat yang dapat dipahami oleh pembaca. Kalimat tersebut memiliki makna lain dari apa yang dimaksud oleh S2.

Dari hasil observasi awal, telah disajikan bagaimana representasi siswa tuna rungu dalam membuat kalimat dan bagaimana mereka menyusun kata-kata menjadi kalimat. Kata-kata dapat berupa angka dan simbol. Mata pelajaran yang banyak menggunakan angka dan simbol salah satunya adalah matematika. Dalam penelitian Mousley (2017) menyebutkan bahwa siswa tuna rungu mampu menyelesaikan permasalahan matematika. Dalam hal ini, perlu mengetahui bagaimana bentuk representasi matematis siswa tuna rungu dalam pembelajaran matematika, agar dapat digunakan sebagai bahan pertimbangan dalam menentukan strategi pembelajaraan yang harus dilakukan oleh pendidik/pembelajar. Salah satu bentuk sajian permasalahan matematika yaitu berupa soal cerita yang menyajikan penerapan teori matematika dalam kehidupan nyata. Dapat dikatakan bahwa penelitian ini bertujuan mendeskripsikan bentuk representasi siswa tuna rungu dalam menyelesaikan soal cerita matematika.

\section{METODE}

\section{Desain Penelitian}

Penelitian terkait bentuk representasi matematis siswa tuna rungu ini merupakan penelitian kualitatif deskriptif. Penelitian kualitatif adalah prosedur penelitian dimana pengamatan perilaku menghasilkan data deskriptif, yaitu berupa kata-kata tertulis maupun lisan (Ceswell, 2012). Penelitian ini menggambarkan bagaimana bentuk representasi yang digunakan oleh siswa tuna rungu dalam menyelesaikan permasalahan yang disajikan berupa soal cerita matematika.

\section{Subjek Penelitian}

Penelitian dilakukan kepada tiga subjek yaitu siswa tuna rungu di SMALBN Banyuwangi. Pemilihan subjek didasari oleh banyak siswa pada sekolah tersebut dengan kemampuan tinggi pada tuna rungu. Ketiga subjek penelitian diberi kode P1, P2 dan P3 agar memudahkan dalam proses analisis selanjutnya.

\section{Instrumen Penelitian}

Instrumen yang digunakan pada penelitian ini berupa soal cerita pada Lembar Kerja. Terdapat dua jenis Lembar Kerja yang digunakan, yaitu lembar kerja dengan soal cerita matematika yang disajikan berupa tulisan saja dan soal cerita yang disajikan dengan tulisan dan gambar. Kedua Lembar Kerja berisi soal cerita yang sama hanya berbeda penyajiannya. Instrumen ini dibuat bertujuan untuk melihat bagaimana siswa mengerjakan soal cerita matematika dan bagaimana representrasi yang digunakan dalam menyelesaikan soal cerita matematika. Jawaban soal cerita oleh siswa selanjutnya dianalisis untuk mengetahui bagaimana proses representasi siswa. Hasil pekerjaan siswa akan diperkuat dengan wawancara yang dilakukan setelah siswa mengerjakan Lembar Kerja yang diberikan. Indikator representasi yang digunakan tertuang pada tabel 1. 
Tabel 1. Indikator Representasi

\begin{tabular}{|c|c|c|}
\hline No & Komponen Representasi & Indikator \\
\hline 1 & Representasi verbal & $\begin{array}{l}\text { - Siswa menggunakan tulisan atau ucapan dalam menuangkan apa yang mereka pahami terkait soal } \\
\text { cerita matematika. } \\
\text { - Siswa menuliskan informasi yang diketahui menggunakan bahasa yang mereka pahami. } \\
\text { - Siswa merencanakan dan melakukan perhitungan menggunakan kalimat tertulis maupun ucapan. } \\
\text { Diadopsi dari Anwar (2017) }\end{array}$ \\
\hline 2 & $\begin{array}{l}\text { Representasi ekspresi } \\
\text { matematis }\end{array}$ & $\begin{array}{l}\text { - Siswa mampu mengidentifikasi masalah dengan baik sehingga siswa dapat membuat simbol untuk } \\
\text { membantu dalam menyelesaiakan permasalahan. }\end{array}$ \\
\hline & & $\begin{array}{ll}2017) & \text { Diadopsi dari Anwar (2017 }\end{array}$ \\
\hline 3 & Representasi visual & $\begin{array}{r}\text { - Siswa dapat menggambarkan, menuangkan masalah yang telah diidentifikasi dengan membuat bentuk } \\
\text { ataupun model sebagai alat untuk menyajikan jawaban maupun membantu memecahkan permsalahan. } \\
\text { Diadopsi dari Rahmad dkk. (2016) }\end{array}$ \\
\hline
\end{tabular}

\section{HASIL DAN PEMBAHASAN}

Berdasarkan hasil analisis tes siswa dan hasil wawancara terdapat representasi eksternal yang dihasilkan oleh ketiga subjek (P1, P2, dan P3). Verbal, numerik, model, gambar, simbol aljabar, tabel, grafik dan bagan adalah beberapa bentuk representasi matematis pemikiran visual siswa yang merupakan bagian tak terpisahkan dari pembelajaran matematika (Surya, 2013). Pada hasil pekerjaan siswa, menunjukkan bahwa terdapat representasi verbal dan representasi ekspresi matematis yang digunakan dalam menjawab soal cerita. Berikut disajikan hasil pekerjaan siswa beserta penjelasannya berdasarkan hasil wawancara.

\section{Representasi Verbal}

Representasi verbal digunakan oleh ketiga subjek. Reperesentasi verbal yang digunakan yaitu berupa tulisan dan perkataan secara langsung dalam bentuk bahasa isyarat. Dalam menyelesaikan soal cerita yang disajikan berupa tulisan, jawaban subjek menunjukkan bahwa subjek kurang memahami maksud soal. Berikut adalah beberapa hasil pekerjaan subjek yang menggunakan representasi verbal yaitu subjek P2 dan P3 seperti yang ditunjukkan pada gambar 3 dan 4.

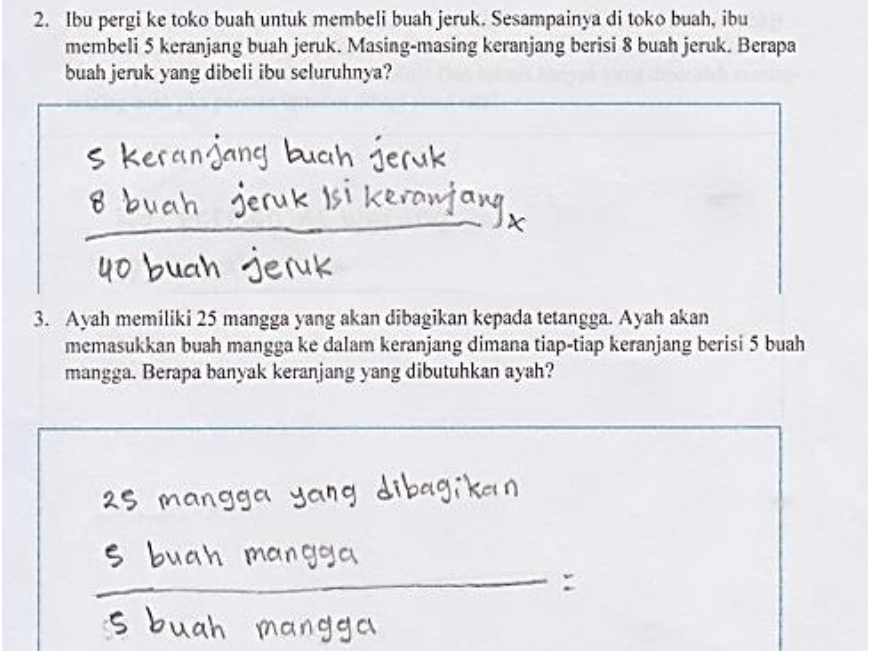

\section{Gambar 3. Hasil Pekerjaan P2}

Pada Gambar 3, subjek P2 menggunakan kalimat untuk menyampaikan hasil representasinya, namun terlihat susunan kalimat tersebut belum sempurna dalam menyajikan jawaban. Walaupun demikian, hasil pekerjaan P2 sudah memenuhi indikator bahwa siswa telah menggunakan tulisan dalam menuangkan apa yang dia pahami serta dapat menceritakan maksud dari pekerjaanya yang disajikan dalam percakapan wawancara dimana wawancara dilakukan oleh peneliti (N), ahli bahasa isyarat dan $\mathrm{P} 2$.

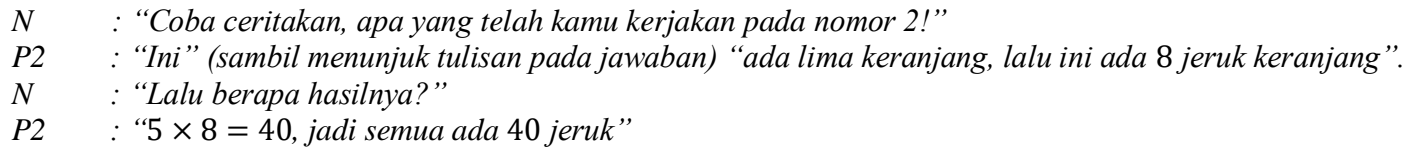


(karena peneliti masih penasaran bagaimana pemahaman siswa terhadap soal, maka peneliti bertanya lagi terakait soal cerita yang disajikan)

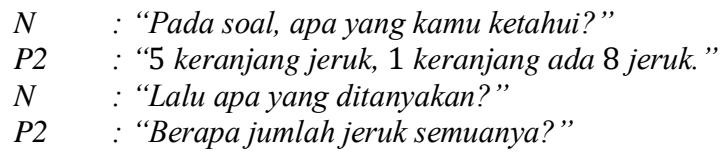

Nomor soal 3 tidak jauh beda dengan nomor 2, P2 menjelaskan bahwa terdapat operasi bagi untuk memperoleh hasil akhirnya. P2 tidak banyak menggunakan kalimat seperti diketahui, ditanyakan, jawab maupun kesimpulan jawaban. Dari hasil pekerjaan P2 dan wawancara, diketahui bahwa dia memahami maksud soal dan merepresentasikan dengan angka dan kata-kata untuk menjawab soal cerita yang diberikan. Gambar 4 menyajikan hasil pekerjaan subjek P3 dalam menyelesaikan soal cerita dengan jenis teks dan gambar.

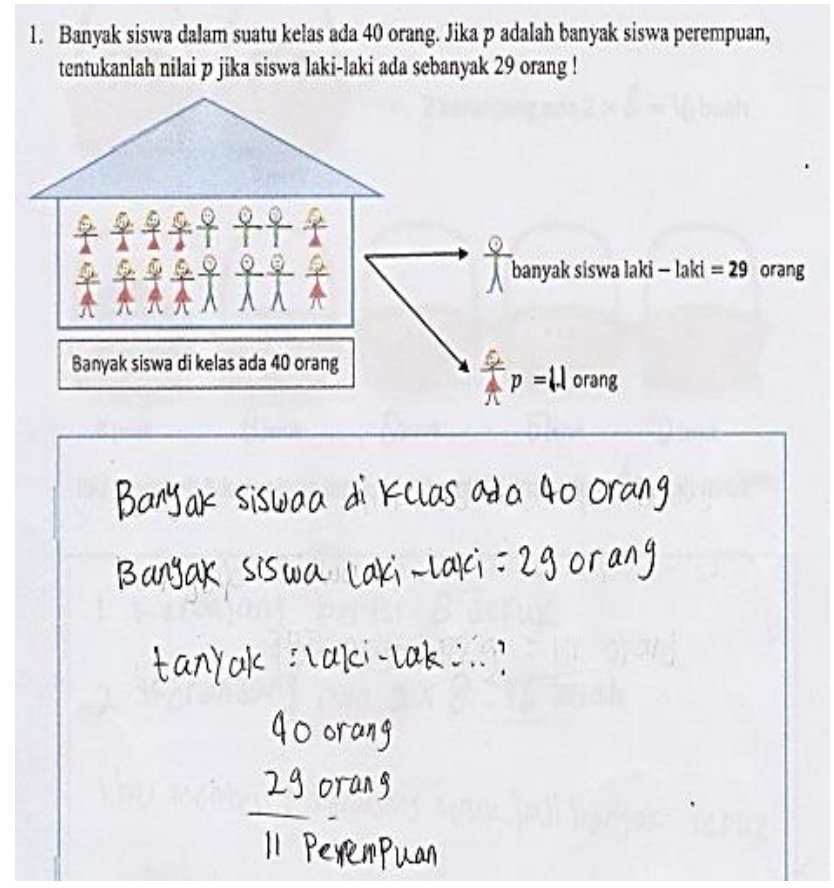

\section{Gambar 4. Hasil Pekerjaan P3}

Pada gambar 4 terlihat subjek P3 menuliskan ulang apa yang dia baca dan apa yang diketahui, lalu menggunakan kalimat dalam menyampaikan hasil representasinya. Subjek P3 memahami apa yang ditanyakan pada soal dan merepresentasikan ulang dengan menuliskannya. Sesuai dengan Anwar (2017), bahwa siswa menuliskan informasi yang diketahui menggunakan bahasa yang mereka pahami dan melakukan perhitungan menggunakan kalimat tertulis. Hal ini menunjukkan bahwa hasil pekerjaan P3 memenuhi indikator representasi verbal dengan didukung penjelasan secara lisan dengan bahasa isyarat yang tertuang dalam cuplikan wawancara berikut.

N $\quad$ : "Apa yang kamu ketahui dari soal ini?"

P3 : "Saya melihat ada siswa-siswa di kelas" (sambil menunjuk gambar pada soal) "ada siswa laki-laki dan perempuan".

N : "Berapa banyak semua siswa?"

P3 : "Semua ada 40 orang"

$N \quad$ : "Lalu, apa yang ditanyakan pada soal?"

P3 : "Ada berapa siswa perempuan."

$N \quad:$ : Berapa siswa perempuannya?"

P3 : "Perempuan ada $40-29=11$ " (sambil menjelaskan dengan bahasa isyarat untuk angka yang diucapkannya) "Perempuan ada 11 orang"

$N \quad:$ :29 itu apa?"

P3 : "Yang laki-laki ada 29" 
Dari penjelasan subjek P3, terdapat kesalahan dalam menuliskan apa yang ditanyakan. Namun demikian, tidak mengubah pemahan siswa terhadap soal yang ditemuinya. P3 merepresentasikan dengan menulis dan menjelaskan yang diketahuinya.

\section{Representasi Visual}

Representasi visual tidak muncul secara lagsung pada hasil pekerjaan ketiga subjek. Ketiga subjek dapat lebih memahami soal cerita yang disajikan dalam bentuk teks dan gambar. Hal tersebut menunjukkan bahwa terdapat representasi internal dimana terjadi proses membayangkan dan menerima gambar sebagai pendukung dalam memahami soal cerita. Setelah memahami soal, subjek menjawab dengan menuliskan pada Lembar Kerja apa yang mereka pikirkan. Penulisan ini menunjukkan bahwa subjek menggunakan bentuk representasi verbal. Hal ini didukung oleh penelitian Marschark (2015), yaitu kemampuan visual-spasial siswa tuna rungu dipengaruhi oleh berbagai faktor yang didasari oleh kemampuan penggunaan bahasa isyarat, dimana bahasa isyarat dan tulisan merupakan cara untuk berkomunikasi secara langsung.

\section{Representasi Ekspresi Matematis}

Representasi ekspresi matematis dilakukan oleh ketiga subjek. Subjek P1 adalah perwakilan subjek yang menggunakan bentuk representasi ekspresi matematis dalam menjawab soal cerita yaitu menuliskan jawaban berupa simbol-simbol dan angka, serta menggunakan metode perkalian dan pembagian untuk memperoleh jawaban untuk nomor soal 2 dan 3 (sesuai hasil wawancara yang dilakukan kepada subjek P1). Hasil pekerjaan oleh subjek P1 dengan jenis soal yang disajikan berupa teks ditunjukkan pada gambar 5. Tidak hanya menjawab soal berjenis teks saja yang memunculkan bentuk representasi ekspresi matematis P1, subjek P1 juga menggunakan simbol-simbol operasi pengurangan, pembagian dan menuliskan angka dari apa yang dia baca pada soal nomor 4 dengan jenis soal teks dan gambar. Pekerjaan ini disajikan pada gambar 6.

2. Ibu pergi ke toko buah untuk membeli buah jeruk. Sesampainya di toko buah, ibu membeli 5 keranjang buah jeruk. Masing-masing keranjang berisi 8 buah jeruk. Berapa buah jeruk yang dibeli ibu seluruhnya?

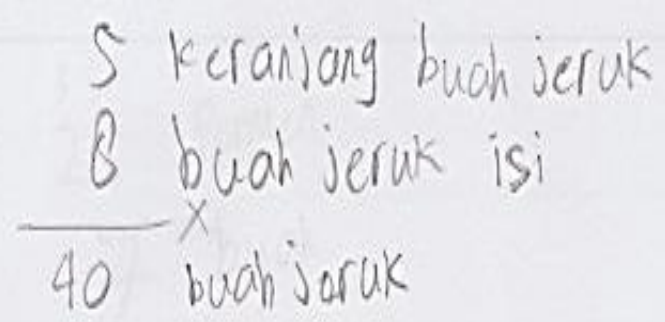

3. Ayah memiliki 25 mangga yang akan dibagikan kepada tetangga. Ayah akan memasukkan buah mangga ke dalam keranjang dimana tiap-tiap keranjang berisi 5 buah mangga. Berapa banyak keranjang yang dibutuhkan ayah?

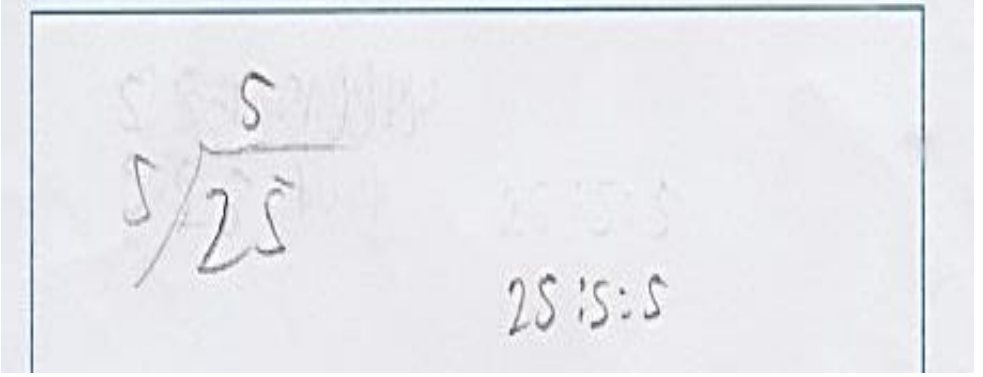

Gambar 5. Hasil Pekerjaan P1 Soal Teks 


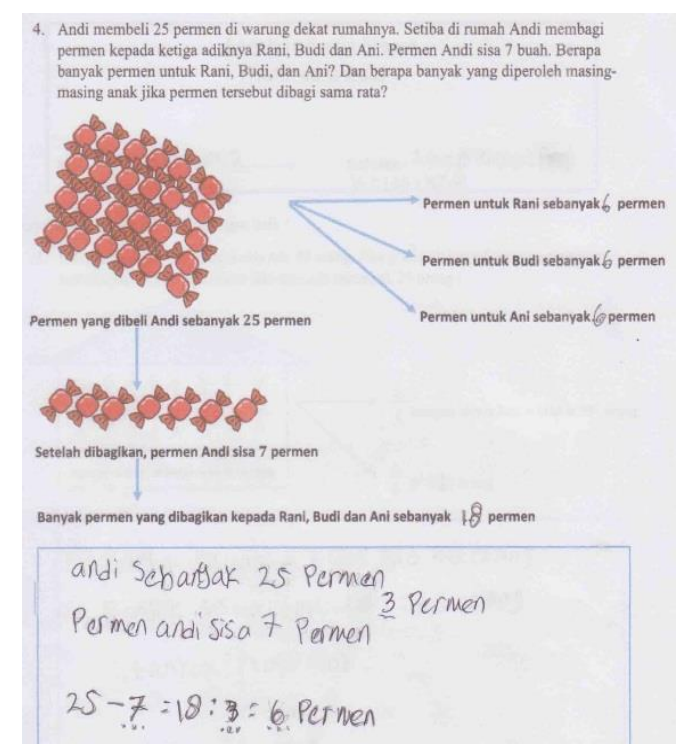

\section{Gambar 6. Hasil Pekerjaan P1 Soal Teks dan Gambar}

Hasil pekerjaan subjek P1 dalam menjawab soal yang disajikan berupa teks dan gambar, memunculkan penggunaan representasi ekspresi matematis. Terlihat pada gambar 6, subjek P1 merepresentasikan dengan angka, kalimat, metode perkalian dan jawaban menggunakan angka dan kata dalam pekerjaannya. Penyajian dari jawaban yang dilakukan ketiga subjek tuna rungu terbatas pada penyusunan kalimat dan pemilihan kata-kata yang digunakan. Walaupun demikian, susunan kalimat dan hasil representasi subjek P1 menunjukkan bahwa siswa memahami maksud soal. Sesuai dengan Anwar (2017), siswa mampu mengidentifikasi masalah dengan baik sehingga siswa dapat membuat simbol untuk membantu dalam menyelesaikan permasalahan.

\section{SIMPULAN}

Hasil analisis ditemukan bahwa terdapat dua tipe bentuk representasi matematis yang muncul dalam menyelesaikan soal cerita, yaitu representasi verbal yang ditunjukkan dengan tulisan kata, angka, huruf, kalimat serta lisan dan representasi ekspresi matematis berupa simbol dan angka. Siswa menuliskan apa yang diketahui serta menggunakan bentuk representasi ekspresi matematis untuk menyampaikan jawaban dari soal cerita. Representasi ekspresi matematis dan representasi verbal banyak muncul pada pekerjaan siswa dalam menjawab soal yang disajikan berupa teks dan gambar. Siswa tuna rungu lebih memahami soal yang disajikan dengan teks dan gambar. Siswa tuna rungu mampu merepresentasikan apa yang mereka pahami terkait soal cerita, membuat simbol-simbol matematis untuk membantu memecahkan permasalahan dan menjelaskan dengan tulisan maupun bahasa isyarat apa yang ada dipikiran mereka.

Berdasarkan hasil penelitian yang dilakukan, pemberian soal matematika dengan jenis teks dan gambar lebih memudahkan siswa dalam memahami soal. Peneliti menyarankan agar guru dapat memfasilitasi siswa tuna rungu agar dapat mengenal gambar yang disertai teks penjelasan. Hal ini bertujuan agar ketika siswa dihadapkan dengan soal jenis teks saja siswa mampu menggambarkan atau memodelkan maksud soal sehingga siswa dapat menggunakan representasi visual.

\section{DAFTAR RUJUKAN}

Anwar, R. B., \& Rahmawati, D. (2017). Symbolic and Verbal Representation Process of Student in Solving Mathematics Problem Based Polya's Stages. International Education Studies, 10(10), 20. https://doi.org/10.5539/ies.v10n10p20

Boonen, A. J. H., van Wesel, F., Jolles, J., \& van der Schoot, M. (2014). The Role of Visual Representation Type, Spatial Ability, and Reading Comprehension in Word Problem Solving: An Item-Level Analysis in Elementary School Children. International Journal of Educational Research, 68, 15-26. https://doi.org/10.1016/j.ijer.2014.08.001

Creswell, J. W. (2012). Educational Research: Planning, Conducting, and Evaluating Quantitative and Qualitative Research. Educational Research (Vol. 4). Boston: Pearson Education.

Debrenti, E. (2015). Visual Representations in Mathematics Teaching: An Experiment with Students. Acta Didactica Napocensia, 8(1), 19-26.

Krawec, J. L. (2014). Problem Representation and Mathematical Problem Solving of Students of Varying Math Ability. Journal of Learning Disabilities, 47(2), 103-115. https://doi.org/10.1177/0022219412436976

Marschark, M., \& Hauser, P. C. (2012). How Deaf Children Learn: What Parents and Teachers Need to Know. New York: Oxford University Press. 
Marschark, M., Shaver, D. M., Nagle, K. M., \& Newman, L. (2015). Predicting the Academic Achievement of Deaf and Hardof-Hearing Students from Individual, Household, Communication, and Educational Factors. Exceptional Children, 81 (3) $350-369$.

Maulida, M A. (2017). Representasi Visual Anak Ditinjau dari Bakat Musik dalam Menyelesaikan Masalah Matematis. Prosiding Seminar Nasional Matematika. Universitas Negeri Malang.

Minarni, A. E., Napitupulu, E., \& Husein, R. (2016). Mathematical Understanding and Representation Ability of Public Junior High School in North Sumatra. Journal on Mathematics Education. Vol 7, No. 1, pp. 45-58

Mousley, K., \& Kelly, R. R. (2017). Developing Deaf Students Fraction Skills Requires Understanding Magnitude and Whole Number Division. Journal of Education and Learning, 7(2), 12. https://doi.org/10.5539/jel.v7n2p12

National Council of Teachers of Mathematics (Ed.). (2000). Principles and Standards for School Mathematics. Reston, VA: National Council of Teachers of Mathematics.

Rahmad, B. A., Ipung, Y., Abdur, R. A., Sisworo, \& Dwi, R. (2016). Mathematical Representation by Students in Building Relational Understanding on Concepts of Area and Perimeter of Rectangle. Educational Research and Reviews, 11(21), 2002-2008. https://doi.org/10.5897/ERR2016.2813

Sealey, V., Deshler, J. M., \& Hazen, K. (2014). Strengthening Student Understanding of Mathematical Language Through Verbal and Written Representations of the Intermediate Value Theorem. PRIMUS, 24(2), 175-190. https://doi.org/10.1080/10511970.2013.858282

Stylianou, D. A. (2010). Teachers' Conceptions of Representation in Middle School Mathematics. Journal of Mathematics Teacher Education, 13(4), 325-343. https://doi.org/10.1007/s10857-010-9143-y

Surya, E., Sabandar, J., Kusumah, Y. S., \& Darhim. (2013). Improving of Junior High School Visual Thinking Representation Ability in Mathematical Problem Solving by CTL. Indonesian Mathematical Society Journal on Mathematics Education. Vol.4, No.1 pp.113-126. https://files.eric.ed.gov/fulltext/EJ1078960.pdf

van Garderen, D., Scheuermann, A., Poch, A., \& Murray, M. M. (2018). Visual Representation in Mathematics: Special Education Teachers' Knowledge and Emphasis for Instruction. Teacher Education and Special Education: The Journal of the Teacher Education Division of the Council for Exceptional Children, 41(1), 7-23. https://doi.org/10.1177/0888406416665448

Solovieva, Y., Rosas, R. Y., Quintanar, L., \& García, M. A. (2013). Symbolic Representation for Introduction of Concept of Decimal System in Mexican School Children. International Education Studies, 6(10), p102. https://doi.org/10.5539/ies.v6n10p102 